\title{
Natural history of synovial hypertrophy in the rheumatoid hand
}

\author{
APRIL G. L. KAY \\ Rheumatology Unit, St. Mary Abbots Hospital, London
}

The late hand deformities in rheumatoid arthritis are familiar (Brewerton, 1957) but knowledge of the sequence of events which lead to these irreversible changes is incomplete.

A study of early rheumatoid hands was undertaken in an attempt to correlate the severity and distribution of early changes with the later development of deformities. This report is of findings during at least 2 years of observation with particular reference to synovial hypertrophy in the joints.

\section{Material \\ The hands of 33 patients ( 4 men and 29 women) with definite but early rheumatoid arthritis are included (Table I). The mean duration of disease at the first observation was 23 months (range 4 to 72). The mean age at onset of disease was 54 years (range 25 to 69). The sheep cell agglutination test (SCAT) was negative in ten patients at the time of the first observation and in seven of these it remained negative throughout the period of observation. The definition of 'early hand' in this series is one without fixed deformities or gross bony destruction at the time of the first observation.}

\section{Method}

A full clinical assessment of the hands was made at approximately annual intervals. One patient did not attend for her second assessment. A standard pro-forma was used which included a diagrammatic representation of all the hand joints. The number of joints showing synovial thickening was noted in each hand, and the severity of synovitis in the metacarpophalangeal and proximal interphalangeal joints was graded 'doubtful', 'minor', 'moderate', or 'major' (see Table IV below). The result was expressed as an involvement quotient (IQ) i.e. the number of joints involved divided by the total number of corresponding joints at risk. Active and passive joint ranges were recorded using a protractor. The distribution of tenosynovitis on the dorsal and flexor aspect of the wrist and hand was observed. Grip strength was measured by taking a mean of three readings using a sphygmanometer bag, $14 \times 7 \cdot 5 \mathrm{~cm}$., inflated to $30 \mathrm{~mm}$. $\mathrm{Hg}$.

\section{Results}

\section{(A) CHANGES IN THE PATTERN OF} INVOLVEMENT

Swelling on the dorsum of the wrist was found at the first assessment in 26 of the 33 patients; in nineteen of these it was bilateral. The IQ of dorsal synovitis at the wrists was $1 \cdot 3 \pm 0.15$ (standard error (SE)) at the first assessment, increasing to a mean of $1.7 \pm 0.12$ (SE) at the third observation (Table II). It was not always possible to differentiate between tendon and joint swelling on the dorsum of the wrist.

Swelling of the flexor aspect of the wrist, usually resulting from tenosynovitis, was uncommon at the first assessment, occurring in only nine patients; in four it was bilateral. The IQ of flexor synovitis at the wrist in both hands was $0.4 \pm 0.12$ (SE) at the first assessment, increasing to $0.6 \pm 0.14$ (SE) at the third observation (Table II).

The IQ of finger metacarpophalangeal (MCP) joint swelling in both hands fell from $3 \cdot 8 \pm 0 \cdot 34$ (SE) at the first assessment to $3 \cdot 7 \pm 0.43$ (SE) at the second and to $3 \cdot 7 \pm 0 \cdot 4$ (SE) at the third (Table III).

\section{Table I Clinical particulars of 33 patients}

No. of patients

Mean duration of disease at first assessment (mths)

Mean period of observation (mths)

Mean age at onset of disease (yrs)

SCAT status

Patients on corticosteroids at first assessment
(4 male; 29 female)

(range 4-72)

(range 21-39)

(range 25-69)

Positive 23 
Table II Involvement quotient of synovitis at the wrists

\begin{tabular}{|c|c|c|c|c|}
\hline \multirow[t]{2}{*}{ Wrist } & \multirow[t]{2}{*}{ Hand } & \multicolumn{3}{|l|}{ Assessment } \\
\hline & & $1^{*}$ & $2^{*}$ & $3^{*}$ \\
\hline Dorsal & $\begin{array}{l}\text { Both } \\
\text { Dominant } \\
\text { Non-dominant }\end{array}$ & $\begin{array}{l}1 \cdot 3 \pm 0.15 \\
0.7 \pm 0.08 \\
0.6 \pm 0.09\end{array}$ & $\begin{array}{l}1.4 \pm 0.15 \\
0.7 \pm 0.08 \\
0.7 \pm 0.08\end{array}$ & $\begin{array}{l}1.7 \pm 0.12 \\
0.9 \pm 0.06 \\
0.8 \pm 0.06\end{array}$ \\
\hline Flexor & $\begin{array}{l}\text { Both } \\
\text { Dominant } \\
\text { Non-dominant }\end{array}$ & $\begin{array}{l}0.4 \pm 0.12 \\
0.3 \pm 0.07 \\
0.1 \pm 0.06\end{array}$ & $\begin{array}{l}0.3 \pm 0.09 \\
0.2 \pm 0.06 \\
0.1 \pm 0.06\end{array}$ & $\begin{array}{l}0.6 \pm 0.14 \\
0.4 \pm 0.09 \\
0.2 \pm 0.06\end{array}$ \\
\hline
\end{tabular}

* Mean value \pm standard error

Table III Involvement quotient of synovitis at the metacarpophalangeal (MCP) and proximal interphalangeal $(P I P)$ joints of the fingers

\begin{tabular}{|c|c|c|c|c|}
\hline \multirow[t]{2}{*}{ Joints } & \multirow[t]{2}{*}{ Hand } & \multicolumn{3}{|l|}{ Assessment } \\
\hline & & $1^{*}$ & $2^{*}$ & $3^{*}$ \\
\hline MCP & $\begin{array}{l}\text { Both } \\
\text { Dominant } \\
\text { Non-dominant }\end{array}$ & $\begin{array}{l}3.8 \pm 0.34 \\
2.0 \pm 0.19 \\
1.8 \pm 0.20\end{array}$ & $\begin{array}{l}3.7 \pm 0.43 \\
1.9 \pm 0.24 \\
1.8 \pm 0.23\end{array}$ & $\begin{array}{l}3.7 \pm 0.40 \\
1.8 \pm 0.21 \\
1.9 \pm 0.21\end{array}$ \\
\hline PIP & $\begin{array}{l}\text { Both } \\
\text { Dominant } \\
\text { Non-dominant }\end{array}$ & $\begin{array}{l}2 \cdot 8 \pm 0.40 \\
1 \cdot 6 \pm 0.24 \\
1 \cdot 2 \pm 0.22\end{array}$ & $\begin{array}{l}1 \cdot 3 \pm 0.30 \\
0.8 \pm 0.18 \\
0.5 \pm 0.15\end{array}$ & $\begin{array}{l}1.0 \pm 0.28 \\
0.6 \pm 0.19 \\
0.4 \pm 0.16\end{array}$ \\
\hline
\end{tabular}

*Mean value \pm standard error

There was a marked fall in the IQ of synovial thickening in the finger proximal interphalangeal (PIP) joints of both hands between the first and second assessments and a lesser fall between the second and third: $2 \cdot 8 \pm 0 \cdot 40$ (SE) at the first, $1 \cdot 3 \pm 0 \cdot 30$ (SE) at the second, and $1.0 \pm 0.28$ (SE) at the third. The difference between the first and second and first and third means are both statistically significant $(P<0.002)$. The fall in inzidence of PIP joint swelling between the first and third observations represented a 63 per cent. rate of remission at these joints. There was also a fall in the relative incidence of 'moderate' and 'major' synovial involvement of the MCP and PIP joints of the fingers at later assessments (Table IV).

The IQ of thumb MCP joint swelling in both hands was $1 \cdot 3 \pm 0 \cdot 14$ (SE) at the first assessment, falling to $0.6 \pm 0.14$ (SE) at the second, and rising again to $1.0 \pm 0.15(\mathrm{SE})$ at the third (Table $\mathrm{V}$, overleaf).

The difference between the means at the first and second assessments are statistically significant ( $P$ $<0.02)$. There was bilateral involvement of the thumb MCP joint in seventeen patients at the first assessment.

The IQ of thumb interphalangeal (IP) joint swelling in both hands was $0.12 \pm 0.07$ (SE) at the first assessment, increasing to $0.24 \pm 0.09$ (SE) at the second and again to $0 \cdot 36 \pm 0 \cdot 12$ (SE) at the third. The differences between these means are not statistically significant (Table V).

Table IV Degree of synovial involvement in the MCP and PIP joints of the fingers of both hands

\begin{tabular}{|c|c|c|c|c|c|c|c|c|c|c|c|}
\hline \multirow[t]{3}{*}{ Joints } & \multirow[t]{3}{*}{ Assessment } & \multicolumn{10}{|c|}{ Synovial involvement } \\
\hline & & \multicolumn{2}{|c|}{ Doubtful } & \multicolumn{2}{|c|}{ Minor } & \multicolumn{2}{|c|}{ Moderate } & \multicolumn{2}{|c|}{ Major } & \multicolumn{2}{|c|}{ Total } \\
\hline & & $D$ & $N-D$ & $D$ & $N-D$ & $D$ & $N-D$ & $D$ & $N-D$ & $D$ & $N-D$ \\
\hline MCP & $\begin{array}{l}1 \\
2 \\
3\end{array}$ & $\begin{array}{r}2 \\
9 \\
10\end{array}$ & $\begin{array}{r}2 \\
14 \\
10\end{array}$ & $\begin{array}{l}30 \\
27 \\
18\end{array}$ & $\begin{array}{l}27 \\
22 \\
19\end{array}$ & $\begin{array}{l}31 \\
23 \\
30\end{array}$ & $\begin{array}{l}24 \\
22 \\
30\end{array}$ & $\begin{array}{l}4 \\
1 \\
1\end{array}$ & $\begin{array}{l}7 \\
1 \\
1\end{array}$ & $\begin{array}{l}67 \\
60 \\
59\end{array}$ & $\begin{array}{l}60 \\
59 \\
60\end{array}$ \\
\hline PIP & $\begin{array}{l}1 \\
2 \\
3\end{array}$ & $\begin{array}{l}1 \\
6 \\
4\end{array}$ & $\begin{array}{l}1 \\
4 \\
4\end{array}$ & $\begin{array}{r}16 \\
11 \\
8\end{array}$ & $\begin{array}{r}17 \\
4 \\
5\end{array}$ & $\begin{array}{r}32 \\
10 \\
8\end{array}$ & $\begin{array}{r}18 \\
4 \\
4\end{array}$ & $\begin{array}{l}2 \\
0 \\
0\end{array}$ & $\begin{array}{l}4 \\
1 \\
1\end{array}$ & $\begin{array}{l}51 \\
27 \\
20\end{array}$ & $\begin{array}{l}40 \\
13 \\
14\end{array}$ \\
\hline
\end{tabular}

D $=$ Dominant hand N-D $=$ Non-dominant hand 
Table V Involvement quotient of synovitis at the MCP and interphalangeal joints of the thumbs

\begin{tabular}{|c|c|c|c|c|}
\hline \multirow[t]{2}{*}{ Joints } & \multirow[t]{2}{*}{ Hand } & \multicolumn{3}{|l|}{ Assessment } \\
\hline & & $1^{*}$ & $2^{*}$ & $3^{*}$ \\
\hline MCP & $\begin{array}{l}\text { Both } \\
\text { Dominant } \\
\text { Non-dominant }\end{array}$ & $\begin{array}{l}1.3 \pm 0.14 \\
0.7 \pm 0.07 \\
0.6 \pm 0.08\end{array}$ & $\begin{array}{l}0.6 \pm 0.14 \\
0.4 \pm 0.05 \\
0.2 \pm 0.09\end{array}$ & $\begin{array}{l}1 \cdot 0 \pm 0 \cdot 15 \\
0 \cdot 5 \pm 0 \cdot 08 \\
0 \cdot 5 \pm 0.08\end{array}$ \\
\hline$\overline{\mathrm{IP}}$ & $\begin{array}{l}\text { Both } \\
\text { Dominant } \\
\text { Non-dominant }\end{array}$ & $\begin{array}{l}0.12 \pm 0.07 \\
0.06 \pm 0.04 \\
0.06 \pm 0.04\end{array}$ & $\begin{array}{l}0.24 \pm 0.09 \\
0.18 \pm 0.07 \\
0.06 \pm 0.04\end{array}$ & $\begin{array}{l}0.36 \pm 0.12 \\
0 \cdot 18 \pm 0.06 \\
0 \cdot 18 \pm 0.06\end{array}$ \\
\hline
\end{tabular}

* Mean value \pm standard error

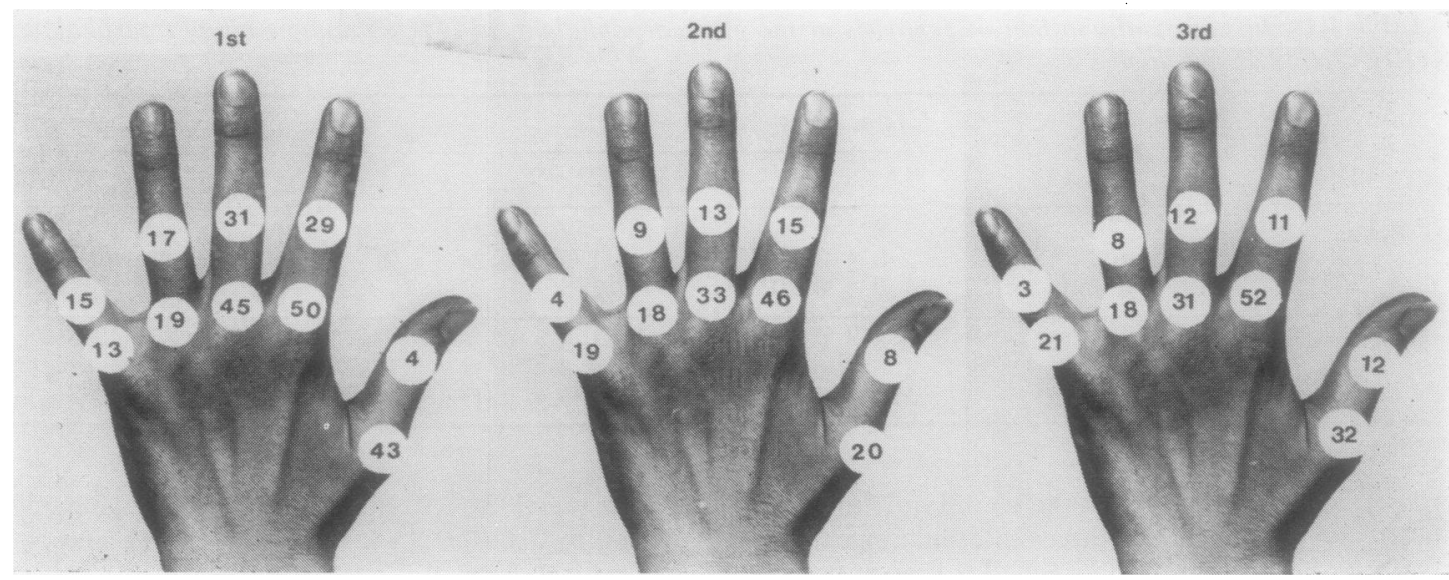

FIGURE Distribution of peripheral joint swelling in both hands at three annual assessments

The distribution of peripheral joint involvement at the first assessment is of interest. The incidence in the index and middle fingers of both the MCP and PIP joints was greatly in excess of that in the ring and little fingers (Figure). The thumb MCP joint also showed a high rate of involvement. This pattern of distribution was maintained at the two subsequent assessments except for a fall in the incidence of index PIP joint involvement at the third assessment.

\section{(B) COMPARISONS BETWEEN DOMINANT AND NON-DOMINANT HANDS}

The difference in incidence of synovial swelling between the dominant and non-dominant hands did not reach statistical significance at any joint, but there was a trend towards a higher incidence of synovitis in the dominant hand at the earlier assessments (Tables III and IV); the difference in the total number of small joints involved was not, however, significant.

The IQ of dorsal synovitis at the wrist was $0.7 \pm$ 0.08 (SE) in the dominant hand and $0.6 \pm 0.09$ (SE) in the non-dominant hand at the first assessment (Table II); where one wrist only was involved it was in every case that of the dominant hand. At subsequent assessments the difference between the dominant and non-dominant hand was either reduced or non-existent.

There was a greater difference in the occurrence of flexor synovitis at the wrist between the dominant and non-dominant hand which was sustained but did not reach statistical significance (Table II).

The IQ of finger MCP joint synovitis in the dominant hand at the first assessment was $2 \cdot 0 \pm 0.19$ (SE) and in the non-dominant hand $1.8 \pm 0.20$ (SE) (Table III). This difference was insignificant and at the second assessment it had disappeared.

The greater incidence of synovial thickening of the PIP joints in the dominant hand persisted but was not statistically significant, and the difference was less at each assessment (Table IV).

Thumb MCP joints were more frequently involved in the dominant hand at the first observation, but the difference had disappeared by the third assessment (Table V).

\section{Tendon sheath involvement}

The major sites of tendon sheath involvement have been noted throughout the study. No ruptured tendons were observed. Detailed observations of the 
distribution and severity of tenosynovitis have recently been undertaken.

The findings in the palmar tendons are of particular interest (Table VI); flexor tenosynovitis is common in all the long finger flexors but major involvement is much more frequent in the index and middle finger flexor tendons than in those to the ring and little fingers. The flexor pollicis longus was less frequently involved than the finger flexors.

Surgery provides a good opportunity to check clinical observations and an operative study of the siting of tendon lesions is reported elsewhere (Backhouse, Kay, Coomes, and Kates, 1971, in press).

\section{Discussion}

The limitations of this study are many. Assessment is dependent on clinical observation, which, as is well known, is subject to error on a decreasing scale as the observer becomes more experienced.

The grosser degrees of synovitis are easy to determine but, for the most part, detailed examination of the hand is concerned with small joints exhibiting only minor degrees of synovial involvement. The clinical experience gained during the study now allows a reasonable degree of accuracy and consistency of observation but there are still a number of problems.

For example, on the flexor aspect of the wrist and hand, palpation of the tendons is limited by the relative thickness of the flexor retinaculum and palmar fascia. Peripheral palmar tendons can be assessed separately but at the wrist the tendons are closely related and superimposed. On the dorsum of the wrist it is often difficult to determine the relative contribution of tendon and joint to the synovial swelling.

The MCP joints are multiaxial, and active in precision as well as power movements, and are thus subjected to frequent and varied usage. The proximal and distal IP joints, in contrast, move in one plane and are only actively involved in power grip (Backhouse, 1968). These functional differences between the MCP and PIP joints may explain, at least in part, the relatively high remission rate at the PIP joints (Table III), and the frequent occurrence of synovitis at the MCP joints of the thumb, index, and middle fingers-those chiefly involved in precision movements.

The fact that significant palmar tenosynovitis has been observed to affect mainly the flexor tendons to the index and middle fingers may also relate to the greater activity of these fingers in both precision and power movements. It is of interest that Brewerton (1957) also found a high incidence of triggering in these fingers. The low incidence of tenosynovitis of the flexor pollicis longus could be due, in part, to the more limited thumb activities; power grip involves the thenar mass and is controlled mainly by the short muscles rather than the distal thumb which is only used to steady larger objects.

The surgical implications of this study demand consideration. The finding of a 63 per cent. remission rate at the PIP joints is a strong argument against early synovectomy. There is some justification for operative intervention at the MCP joints but, with even a low remission rate, synovectomy if carried out too early may be unnecessary.

More information is needed about the natural history of rheumatoid arthritis in a wide variety of joints before it is possible to make a definitive statement on the value of early synovectomy.

\section{Summary}

The hands of 33 patients with early rheumatoid arthritis were observed for $2 \frac{1}{2}$ years. The findings were as follows:

(1) Synovitis is common and usually persistent on the dorsum of the wrist and in the metacarpophalangeal joints.

(2) There is a 63 per cent. remission rate of synovitis at the proximal interphalangeal joints; synovectomy of these joints is therefore seldom justified.

(3) Although synovial joint involvement tends to occur earlier in the dominant hand, there is no statistical difference between the number and distribution of joints showing svnovitis in the dominant and non-dominant hand.

I should like to thank Drs. E. N. Coomes, A. St. J. Dixon, H. Goodman, O. Savage, and J. T. Scott for allowing me to see their patients, Drs. K. M. Backhouse and A. St. J.

Table VI Occurrence, severity, and distribution of tenosynovitis of the flexor tendons in ninety hands

\begin{tabular}{|c|c|c|c|c|}
\hline \multirow[t]{2}{*}{ Flexor tendons } & \multicolumn{4}{|c|}{ Tenosynovitis } \\
\hline & Minor & Moderate & Major & Total \\
\hline $\begin{array}{l}\text { Thumb } \\
\text { Index } \\
\text { Middle } \\
\text { Ring } \\
\text { Little }\end{array}$ & $\begin{array}{l}34 \\
15 \\
14 \\
25 \\
28\end{array}$ & $\begin{array}{l}27 \\
39 \\
34 \\
42 \\
47\end{array}$ & $\begin{array}{r}2 \\
32 \\
39 \\
13 \\
6\end{array}$ & $\begin{array}{l}63 \\
86 \\
87 \\
80 \\
81\end{array}$ \\
\hline
\end{tabular}


Dixon for their advice and criticism, and Mrs. Sparks for secretarial assistance.
This work was made possible by a generous grant from the Arthritis and Rheumatism Council for Research.

\section{References}

Brewerton, D. A. (1957) Ann. rheum. Dis., 16, 183 (Hand deformities in rheumatoid disease).

BACKHOUSE, K. M. (1968) Ann. roy. Coll. Surg., 43, 154 (The mechanics of normal digital control in the hand and an analysis of the ulnar drift of rheumatoid arthritis).

, KAY, A. G. L., COOMES,
in the rheumatoid hand). 